\title{
Continuity of Cancer Care and Collaboration Between Family Physicians and Oncologists: Results of a Randomized Clinical Trial
}

\author{
Michèle Aubin, MD, PbD, CCFP \\ Lucie Vézina, MA \\ René Verreault, $M D, P b D, C C F P$ \\ Sébastien Simard, $\mathrm{PbD}$ \\ Éveline Hudon, MD, MA \\ Jean-François Desbiens, RN, PbD \\ Lise Fillion, RN, $\mathrm{PbD}$ \\ Serge Dumont, $\mathrm{PbD}$ \\ André Tourigny, MD, MBA \\ Serge Daneault, $M D, P b D$
}

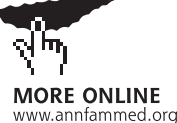

Conflicts of interest: authors report none.

\author{
CORRESPONDING AUTHOR \\ Michèle Aubin \\ Département de médecine familiale \\ et médecine d'urgence \\ Université Laval, Pavillon Ferdinand-Vandry \\ 1050 Ave de la Médecine, Room 4617 \\ Quebec, Canada, G1V 0A6 \\ michele.aubin@mfa.ulaval.ca
}

\begin{abstract}
PURPOSE Collaboration between family physicians (FPs) and oncologists can be challenging. We present the results of a randomized clinical trial of an intervention designed to improve continuity of care and interprofessional collaboration, as perceived by patients with lung cancer and their FPs.

METHODS The intervention included (1) supplying FPs with standardized summaries related to each patient, (2) recommending that patients see their FP after receiving the cancer diagnosis, (3) supplying the oncology team with patient information resulting from FP visits, and (4) providing patients with priority access to FPs as needed. A total of 206 patients with newly diagnosed lung cancer were randomly assigned to the intervention $(n=104)$ or control group $(n=102)$, and $86.4 \%$ of involved FPs participated. Perceptions of continuity of care and interprofessional collaboration were assessed every 3 months for patients and at baseline and at the end of the study for FPs. Patient distress and health service utilization were also assessed.
\end{abstract}

RESULTS Patients and FPs in the intervention group perceived better interprofessional collaboration (patients: $P<.0001 ; F P s: P=.0006)$ than those in the control group. Patients reported better informational continuity $(P=.001)$ and management continuity $(P=.05)$ compared to the control group, but no differences were found for FPs (information: $P=.22$; management: $P=.13$ ). No effect was found with regard to patient distress or health service utilization.

CONCLUSIONS This intervention improved patient and FP perception of interprofessional collaboration, but its effectiveness on continuity of care was less clear for FPs than for patients. Additional strategies should be considered to sustainably improve continuity of care and interprofessional collaboration.

Ann Fam Med 2021;19:117-125. https://doi.org/10.1370/afm.2643.

\section{INTRODUCTION}

$\mathrm{P}$ atients with cancer often experience fragmented health care. ${ }^{1-3}$ Whereas family physicians (FPs) seek to provide continuous and comprehensive care, ${ }^{4-6}$ they can lose contact with patients during the course of cancer treatment. ${ }^{7-9}$ Given the current state of suboptimal continuity of care, ${ }^{9-13}$ experts have emphasized the need to develop more effective communication mechanisms between oncologists and FPs. ${ }^{1,2,6,13-15}$

According to Haggerty and colleagues, ${ }^{16,17}$ continuity of care is the result of availability and good information flow regarding prior events (informational continuity), ongoing relationships between patients and their providers (relational continuity), and the availability of timely complementary services within a shared plan (management continuity).

Systematic reviews highlight the importance of good circulation of information between health professionals to improve coordination of care. ${ }^{2,15,18,19}$ Aiming to achieve that goal, we implemented an intervention in an ambulatory oncology clinic treating patients with lung cancer. We report on the effect of this intervention on patients' and their FPs' 
perceptions of continuity of care and interprofessional collaboration.

\section{METHODS}

\section{Study Design and Participant Selection}

We conducted a randomized trial during the period June 2010 to December 2014 at the Institut universitaire de cardiologie et de pneumologie de Québec (IUCPQ), a tertiary care hospital in Québec, Canada. The oncology team includes nurse navigators who meet each patient with lung cancer to assess their needs, provide information and support, and act as resources throughout their cancer journey. These nurse navigators recruited patients for the trial. Inclusion criteria were as follows: (1) a recent diagnosis of nonsurgical lung cancer ( $85 \%$ of all cases). These patients are followed by a single team, thus facilitating the implementation of the intervention. The 5 -year survival rate is approximately $15 \%$; nonetheless, this time frame allowed us to capture patient perceptions at different phases of their disease trajectory $y_{i}(2)$ having an FP, and (3) having at least a 3-month estimated life expectancy. With the use of a computer-generated randomization list, patients were randomly assigned to the experimental or control group. Patients provided their FP's contact information, and FPs were sent a letter to inform them of their patient's participation and to recruit them, they were assigned to the same group as their patient. Some FPs $(n=16)$ had 2 patients enrolled, but they responded only once to the study questionnaires because their perception of continuity of cancer care and interprofessional collaboration was assessed in general and was not related to specific patients. Their responses were imputed twice to account for their double participation to the study. To prevent contamination between groups, their second patient enrolled was assigned to the same group as the first. There was no blinding. Both patients and FPs in the experimental group received the intervention details and signed an informed consent form, but those in the control group signed a different consent form and were informed of the trial aims without the intervention details. The trial was approved by the IUCPQ Research Ethics Committee and was registered at ClinicalTrials.gov on July 8, 2011 (NCT01389739).

\section{Intervention}

The intervention was based on prior study results on the role of FPs in cancer care $7,20,21$ and developed according to published strategies to improve interprofessional collaboration. ${ }^{22}$ We conducted a pilot study with 20 FPs from different settings and the IUCPQ oncology team to assess the feasibility/acceptability of the intervention. To prevent contamination between groups, a research nurse was recruited to administer the intervention in the experimental group, in addition to usual care. The intervention comprised (1) a 1-page standardized summary faxed to the FP every 3 months, which included information on lung cancer, patient functional status, prognosis, treatment plan, oncologist recommendations, and nurse navigator contact details $s_{i}(2)$ systematic recommendations to patients to see their FP within the first 3 months after diagnosis. The research nurse offered help to organize the appointment, and subsequent appointments were arranged between the FP and the patient $t_{i}(3)$ systematic fax transmissions from the FP to the oncology team of patient information resulting from FP visits. The initial summary included a list of active problems, medications and other treatments, and recommendations $_{i}$ FPs indicated their involvement in home care, palliative care, and to a 24-hours-a-day, 7-days-a-week, on-call system. Subsequent summaries indicated symptom changes or changes in medication/treatment ${ }_{i}(4)$ the research nurse was instructed to schedule priority access to FPs for patients with minor problems unrelated to cancer if patients were unable to do so.

\section{Data Collection and Study Instruments}

During appointments at the oncology clinic or at home, depending on their preference, patients completed questionnaires at baseline and every 3 months for 18 months or until death. For each study period, functional status was assessed according to the Eastern Collaborative Oncology Group scale. ${ }^{23}$ Patients indicated their perceived FP pattern of care classified according to Norman et $\mathrm{al}^{24}$ as sequential (no FP involvement, patients receiving most care by the oncology team and eventually returning to their FP), parallel (FP involved for noncancer problems), or shared (FP and oncology team both involved).

Patients then completed questionnaires for the 2 primary outcomes of perceived collaboration between the FP and the oncology team, ${ }_{1}^{25}$ as assessed with a 5 -point scale for global assessment of interprofessional cooperation ( 1 = strongly disagree, $5=$ strongly agree), and perceived continuity of care as assessed with questions adapted from Haggerty et al's questionnaire on evaluation of primary care services, ${ }^{26-28}$ which was derived from the Primary Care Assessment Tool. ${ }^{29,30}$ The questionnaire used the mean score of a 5 -point scale ( $1=$ not at all, $5=$ totally) for the 3 dimensions of continuity: relational ( 7 questions related to the patient-FP relationship, such as the importance given by the FP to the patients' preoccupations, values, and personal problems and FP knowledge of the patient's social context; this dimension of continuity 
was measured at baseline only for descriptive purposes), informational (6 questions assessing the need for patients to repeat their history to each provider, FP awareness of test results and cancer treatments), and management (5 questions to determine if the oncology team and FP were giving similar recommendations and seemed to work well together and to know their roles). Informational and management continuity were measured at each study period, and scores were converted to proportions of patients perceiving good continuity of care (scores $\geq 4$; range 1-5).

Patients also completed questionnaires for the 2 secondary outcomes of distress as assessed with the Hospital Anxiety and Depression Scale, ${ }^{31,32}$ a 14 -item questionnaire with a 0 to 42 score range; distress is presented as the proportion of patients with clinically significant distress (score $\geq 15$ ), and health service utilization (hospitalizations and visits to the emergency department [ED] as found in patients' medical files). The FPs completed mailed questionnaires at baseline and at the end of their patient's participation in the study. Questions mirrored those of patients on perceived collaboration with oncologists and continuity of care.

\section{Analysis}

Based on a global score of $2.2 \pm 0.78$ (range 1-5)

for perceived collaboration between FPs and the oncology team ${ }^{25}$ (with $\alpha=.05$ and a power of $80 \%)$, a sample of 206 patients (103 per group) would allow for the detection of a 0.3 -point difference between groups. Adherence to the intervention was assessed by determining the proportions of summaries sent to FPs, summaries sent by FPs to the oncology team, FP appointments given to patients, and contacts between FPs and nurse navigators. Statistical tests on means and proportions ( $t$ test, $\chi^{2}, F$ ) served to compare participant characteristics and baseline outcome measures between groups. Mixed models for repeated measures assessed the intervention effectiveness on primary and secondary outcomes. Missing data for patients who died ( $\mathrm{n}=109)$ were not imputed. For patients who withdrew $(\mathrm{n}=16)$ or were transferred to a palliative care unit, their last data collected were carried over to conduct intention-to-treat analyses. Results were equivalent with or without imputing missing data $a_{i}$ therefore, only results without imputation are presented. All tests used a 2-sided .05 statistical significance level and were performed with SAS software version 9.4 (SAS Institute Inc).

\section{RESULTS}

\section{Participants}

Of 259 eligible patients, 206 (79.5\%) were recruited and randomly allocated to the experimental $(\mathrm{n}=104)$ or control $(\mathrm{n}=102)$ group, and a total of $152 \mathrm{FPs}$ (86.4\%) participated (Figure 1). Baseline patient and FP characteristics were well balanced between the groups, with the exception of patient perception of pattern of care (Tables 1 and 2, Supplemental Tables 1 and 2, https://www.AnnFamMed.org/content/19/2/117/suppl/ DC1/). More patients in the control group perceived a sequential or shared pattern of care compared with those in the experimental group $(P=.04)$ (Table 2). Patients and FPs had different perceptions of pattern of care; $57.2 \%$ of FPs reported a shared pattern of care compared with $26.7 \%$ of patients $(P<.0001)$ (Table 2 , Supplemental Table 2).
Figure 1. Patient flow diagram.

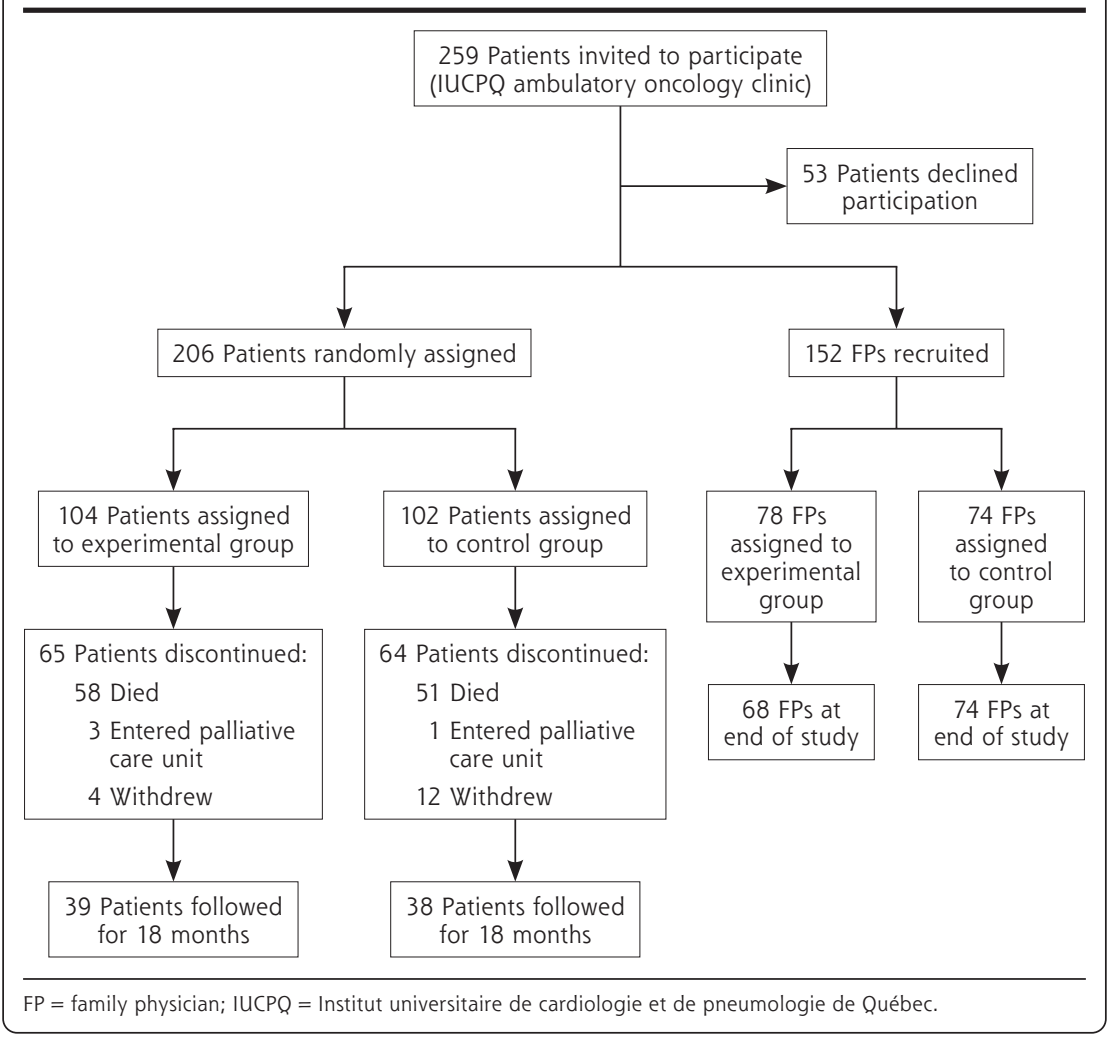


Table 1. Baseline Patient Characteristics

\begin{tabular}{|c|c|c|c|}
\hline Characteristic & $\begin{array}{l}\text { Experimental } \\
\quad(n=104)\end{array}$ & $\begin{array}{l}\text { Control } \\
(n=102)\end{array}$ & $\begin{array}{c}P \\
\text { Value }\end{array}$ \\
\hline Age, mean (SD), y & $64.2(9.0)$ & $64.6(8.4)$ & .73 \\
\hline Male, No. (\%) & $61(58.7)$ & $58(56.9)$ & .79 \\
\hline Working status, No. (\%) & & & .62 \\
\hline Full-time & $34(32.7)$ & $28(27.5)$ & \\
\hline Part-time & $10(9.6)$ & $13(12.7)$ & \\
\hline Not working & $60(57.7)$ & $61(59.8)$ & \\
\hline $\begin{array}{l}\text { Type of lung cancer, } \\
\text { No. (\%) }\end{array}$ & & & .32 \\
\hline $\begin{array}{l}\text { Squamous cell } \\
\text { carcinoma }\end{array}$ & $14(13.5)$ & 22 (21.6) & \\
\hline $\begin{array}{l}\text { Adenomatous } \\
\text { carcinoma }\end{array}$ & $53(51.0)$ & $47(46.1)$ & \\
\hline Small cell carcinoma & $24(23.1)$ & $23(22.5)$ & \\
\hline $\begin{array}{l}\text { Other non-small cell } \\
\text { carcinoma }\end{array}$ & $13(12.5)$ & $10(9.8)$ & \\
\hline Treatment, No. (\%) & & & .74 \\
\hline Chemotherapy & $36(34.6)$ & $43(42.2)$ & \\
\hline Radiation & $5(4.8)$ & $4(3.9)$ & \\
\hline $\begin{array}{l}\text { Chemotherapy and } \\
\text { radiation }\end{array}$ & $57(54.8)$ & $50(49.0)$ & \\
\hline No treatment & $6(5.8)$ & $5(4.9)$ & \\
\hline Metastasis, No. (\%) & $49(47.1)$ & $53(52.0)$ & .58 \\
\hline $\begin{array}{l}\text { TNM classification, } \\
\text { No. (\%) }\end{array}$ & & & .57 \\
\hline Stage 1 and 2 & $7(6.7)$ & $3(2.9)$ & \\
\hline Stage 3 & $34(32.7)$ & $30(29.4)$ & \\
\hline Stage 4 & $36(34.6)$ & $43(42.2)$ & \\
\hline Unclassified ${ }^{a}$ & $27(26.0)$ & $26(25.5)$ & \\
\hline $\begin{array}{l}\text { Functional status, } \\
\text { No. }(\%)^{\mathrm{b}}\end{array}$ & & & .11 \\
\hline Active & $56(53.8)$ & $41(40.2)$ & \\
\hline $\begin{array}{l}\text { Ambulatory but both- } \\
\text { ered by symptoms }\end{array}$ & $33(31.7)$ & $36(35.3)$ & \\
\hline$<50 \%$ bedridden & $11(10.6)$ & $12(11.8)$ & \\
\hline$\geq 50 \%$ bedridden & $4(3.8)$ & $12(11.8)$ & \\
\hline Always bedridden & $0(0)$ & $1(1.0)$ & \\
\hline
\end{tabular}

TNM = TNM Classification of Malignant Tumors.

a Most patients had small cell carcinoma, for which there is no TNM classification.

${ }^{b}$ Functional status according to Eastern Collaborative Oncology Group scale.

\section{Adherence to Intervention}

All summaries were sent to FPs, with the exception of 1 because the patient died soon after recruitment. Two-thirds of patients in the experimental group consulted their FP in the first 3 study months compared with $54 \%$ of patients in the control group $(P<.01)$. For other study periods, more patients in the experimental group consulted their FP compared with patients in the control group, but the difference between groups was no longer statistically significant after 9 months of follow-up. Almost three-fourths of FPs were compliant in returning their summaries to the oncology team, $47 \%$ returned all, and $27.2 \%$
Table 2. Baseline Patient Outcome Measures

\begin{tabular}{|c|c|c|c|}
\hline Outcome Measure & $\begin{array}{l}\text { Experimental } \\
(n=104)\end{array}$ & $\begin{array}{l}\text { Control } \\
(n=102)\end{array}$ & $\begin{array}{c}P \\
\text { Value }\end{array}$ \\
\hline $\begin{array}{l}\text { Interprofessional collab- } \\
\text { oration, mean (SD) }\end{array}$ & $3.2(1.0)$ & $3.2(1.0)$ & .77 \\
\hline \multicolumn{4}{|l|}{$\begin{array}{l}\text { Relational continuity, } \\
\text { mean (SD) }\end{array}$} \\
\hline Knowledge of patient & $3.6(0.8)$ & $3.5(0.8)$ & .93 \\
\hline $\begin{array}{l}\text { Partnership and } \\
\text { confidence }\end{array}$ & $3.9(0.6)$ & $3.8(0.8)$ & .17 \\
\hline \multicolumn{3}{|l|}{ Pattern of care, No. (\%) } & .04 \\
\hline Sequentialc & $13(12.5)$ & $24(23.5)$ & \\
\hline Parallel $^{d}$ & $66(63.5)$ & $48(47.1)$ & \\
\hline Shared & $25(24.0)$ & $30(29.4)$ & \\
\hline Distress, No. $(\%)^{f}$ & $6(5.8)$ & $10(9.8)$ & .28 \\
\hline $\begin{array}{l}\text { Good informational } \\
\text { continuity, No. }(\%)^{g}\end{array}$ & $18(32.7)$ & $21(36.2)$ & .7 \\
\hline $\begin{array}{l}\text { Good management } \\
\text { continuity, No. (\%)g }\end{array}$ & $43(78.2)$ & $47(81.0)$ & .71 \\
\hline \multicolumn{4}{|l|}{ FP = family physician. } \\
\hline \multicolumn{4}{|c|}{$\begin{array}{l}\text { a Score range 1-5; a higher score indicates a better perception of interprofes- } \\
\text { sional collaboration. } \\
\text { b Score range 1-5; a higher score indicates a better perception of relational } \\
\text { continuity. } \\
\text { ' FPs not involved when specialists are involved. } \\
\text { d FPs involved with health problems unrelated to cancer. } \\
\text { e FPs and oncology team both involved in cancer care. } \\
\text { f Distress based on Hospital Anxiety Depression Scale. Patients with a score } \geq 15 \\
\text { (range } 0-42 \text { ) considered to have clinically significant distress. } \\
9 \text { Responses given only by patients who had seen their FP ( } \mathrm{N}_{\text {experimental }}=55 \text {, } \\
\mathrm{N}_{\text {control }}=58 \text { ); patients with a score } \geq 4 \text { (range } 1-5 \text { ) perceived good continuity. }\end{array}$} \\
\hline
\end{tabular}

omitted 1. Most FPs (89.7\%) agreed to prioritize appointments for their patients; more than $83 \%$ of patients were able to get an appointment the same or next day. Other than the exchange of summaries, contacts between FPs and the oncology team were limited (5 contacts by FPs or research nurse during the entire study). A total of $70 \%$ of FPs indicated that they would offer home care (themselves: $61 \%$; a colleague at their clinic: $9 \%$ ) if necessary.

\section{Effect of Intervention}

At baseline, patients and FPs in both groups perceived good interprofessional collaboration (Table 2, Supplemental Table 2). Patients reported good relational continuity of care, and most indicated good management continuity. However, a smaller proportion of FPs in both groups perceived good management continuity, and for both patients and FPs, approximately one-third perceived good informational continuity.

After intervention implementation, patients and FPs in the experimental group perceived better interprofessional collaboration compared with patients in the control group (patients: $P<.0001$; FPs: $P=.0006$ ) (Figures $2 \mathrm{~A}$ and $2 \mathrm{~B}$ ). A greater proportion of patients in the experimental group reported good informational 
Figure 2. Effect of the intervention on the global assessment of interprofessional collaboration between family physician and the oncology team.

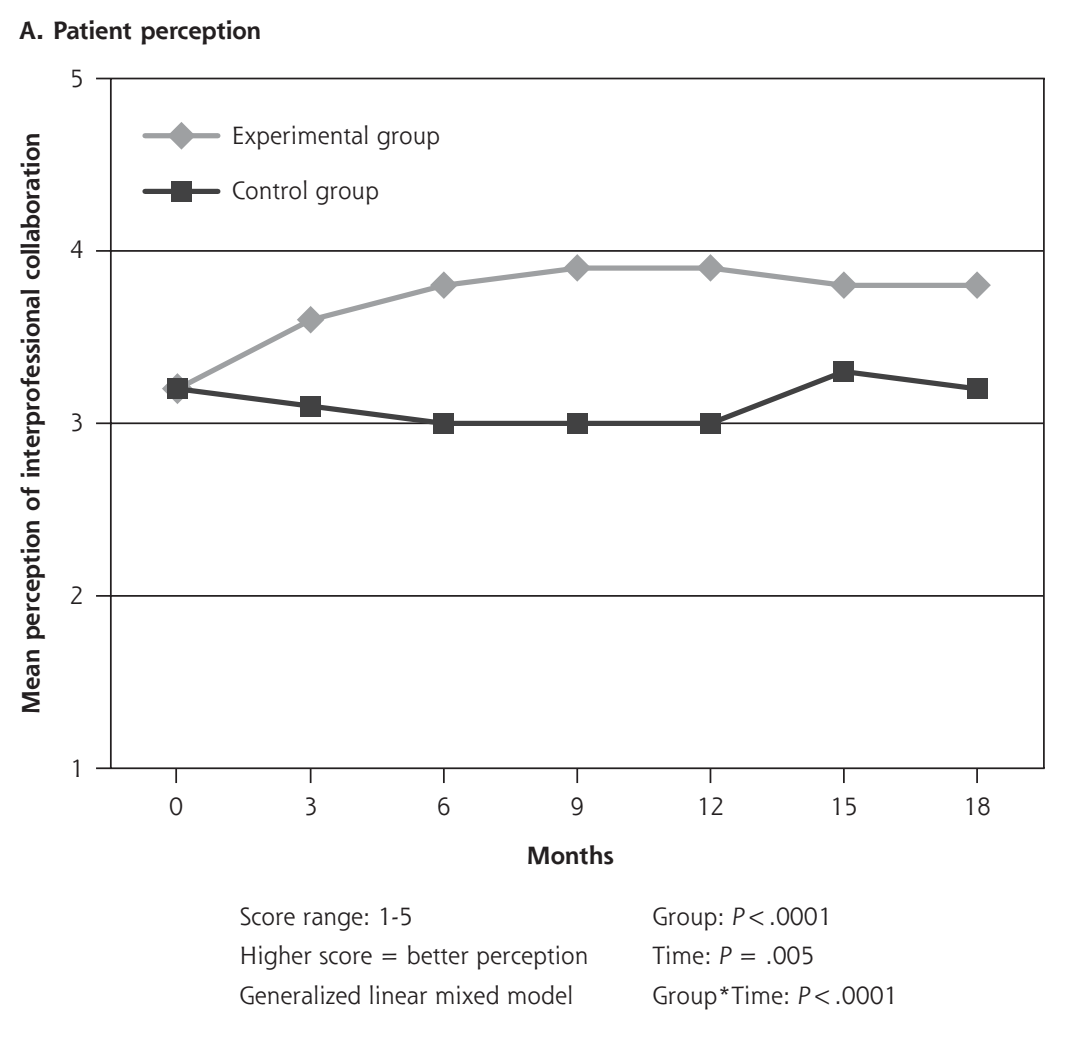

B. Family physician perception

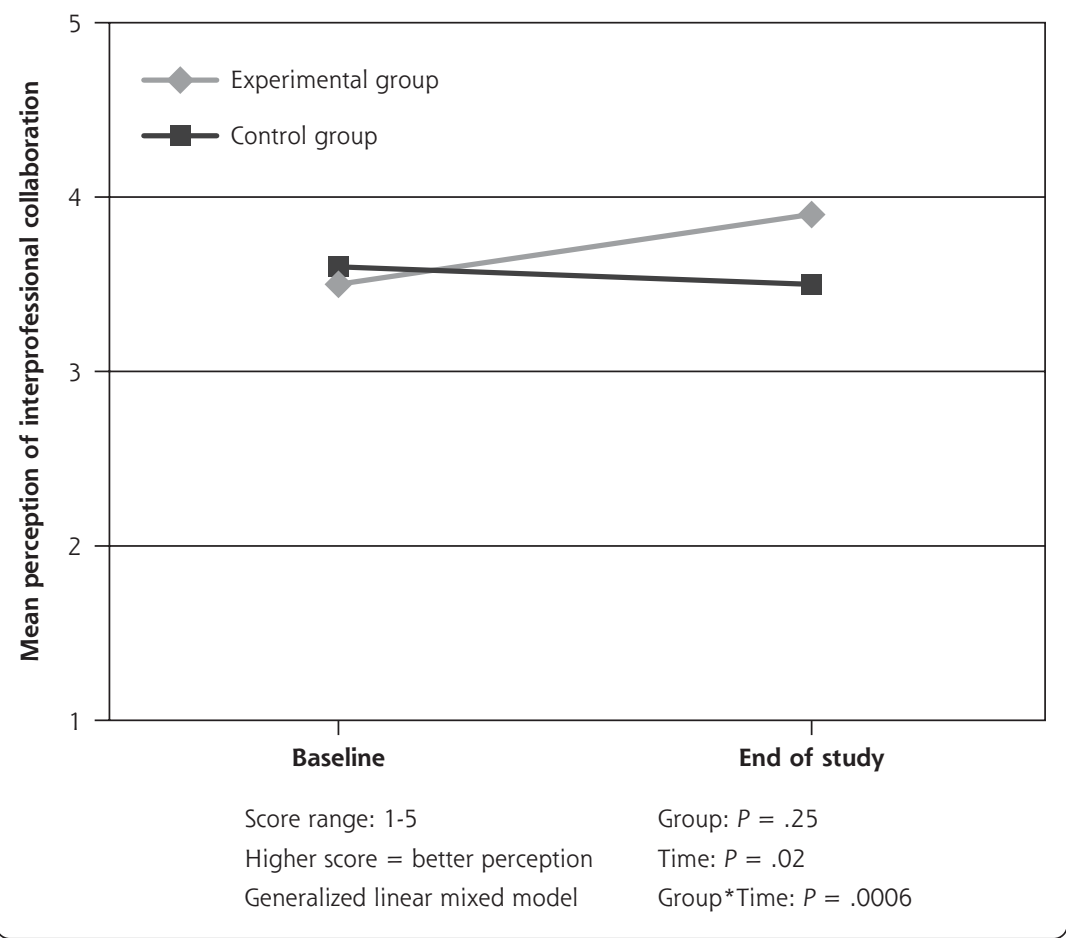

continuity $(P=.001)$ and good management continuity $(P=.05)$ compared with patients in the control group (Supplemental Figures $1 \mathrm{~A}$ and $2 \mathrm{~A}$, https://www.Ann FamMed.org/content/19/2/117/ suppl/DC1/). Although more FPs in the experimental group reported good informational and management continuity, the difference compared to the control group was not statistically significant (Supplemental Figures $1 \mathrm{~B}$ and 2B, https://www.AnnFamMed.org/ content/19/2/117/suppl/DC1/).

Family physicians reported different patterns of care after the intervention $(P=.02)$, but this was not reflected in the patient perception of FP pattern of care $(P=.32)$ (Figures $3 \mathrm{~A}$ and $3 \mathrm{~B})$. For all study periods, the mean number of FP visits by patients in both groups was significantly greater for those perceiving shared care compared with patients perceiving a parallel or sequential pattern of care (Supplemental Figure 3, https://www.AnnFamMed.org/ content/19/2/117/suppl/DC1/). There was no statistically significant difference in the mean number of FP visits between the experimental and control groups.

Three months after intervention implementation, hospitalizations and ED visits were decreased in the experimental group (hospitalizations: experimental $17 \%$ vs control $29 \%$; $P=.05$; ED visits: experimental $24 \%$ vs control $36 \% ; P=.05$ ). However, this decrease was not found for other study periods.

Throughout the study for patients in both groups, there was a significant association between the perception of shared care and a better assessment of interprofessional collaboration $(P<.0001)$ and informational $(P=.02)$ and management $(P=.006)$ continuity of care. The proportion of patients with clinically significant distress 
remained low throughout the study and was not influenced by the intervention $(P=.39)$ (Figure 4$)$. communication between FPs and the oncology team, this might also explain the lack of effect on patient distress

\section{DISCUSSION}

Our intervention increased patient and FP perception of interprofessional collaboration and improved patient perception of informational and management continuity of care. These improvements appeared early and were maintained over time. However, the intervention did not significantly affect FP perception of informational or management continuity; informational and management continuity improved in both the experimental and control groups. The scarce contacts between FPs and the oncology team, in addition to the exchange of summaries, might explain these results.

The intervention had a modest effect on patient hospitalizations and ED visits only at the beginning of the study. The severity of lung cancer, requiring many health services, might have contributed to this limited effect. One-half of participants had metastases, the majority were Stage 3 to 4 , and one-half died during the study. Several studies have reported a favorable effect of continuity of care on health service utilization, ${ }^{33-36}$ but those studies were conducted with other populations, and most used only measures of relational continuity. More research is needed to isolate the influence of informational and management continuity of care on these outcomes. . $^{37,38}$

The intervention did not influence patient distress. Very few patients reported clinically significant distress throughout the study. Nurse navigators might have given support to patients in both groups, thus contributing to the low proportion of distressed patients. Given that the intervention mainly targeted
Figure 3. Family physician pattern of care at baseline and at the end of the study.

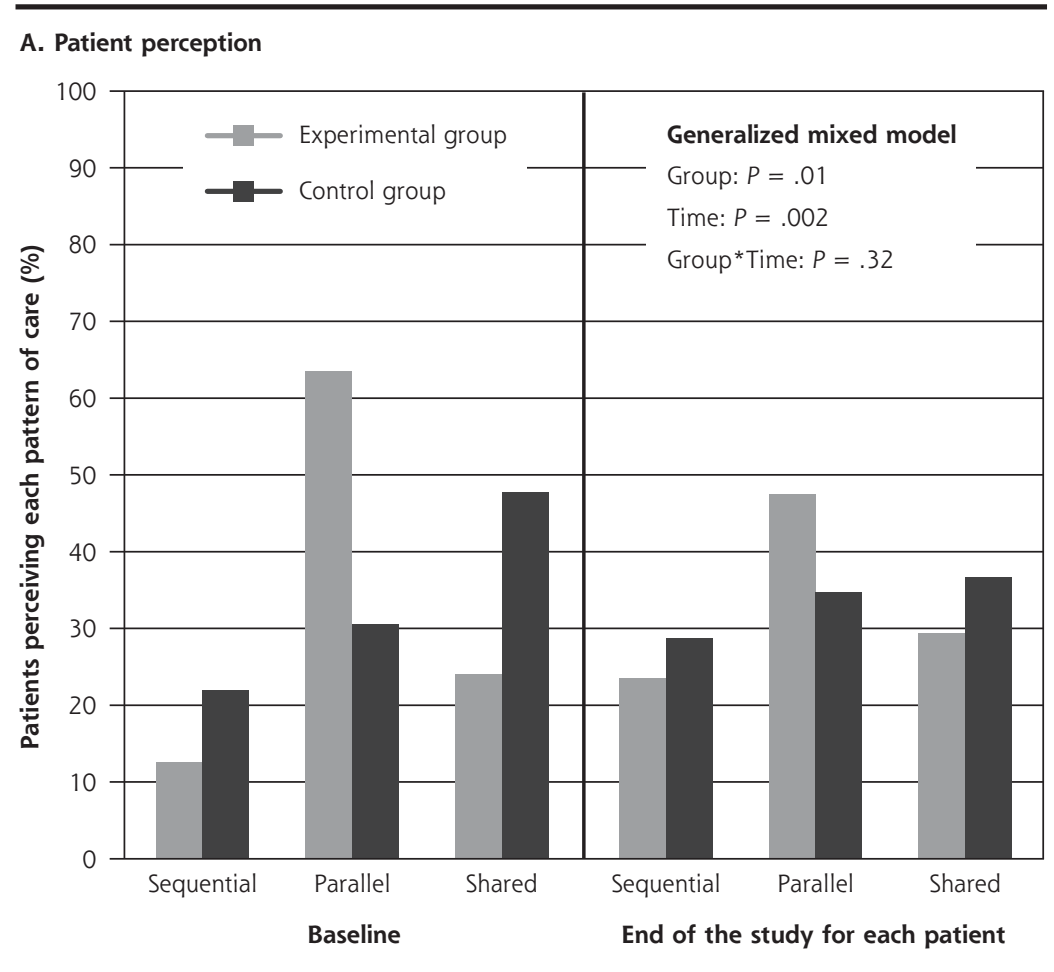

B. Family physician perception

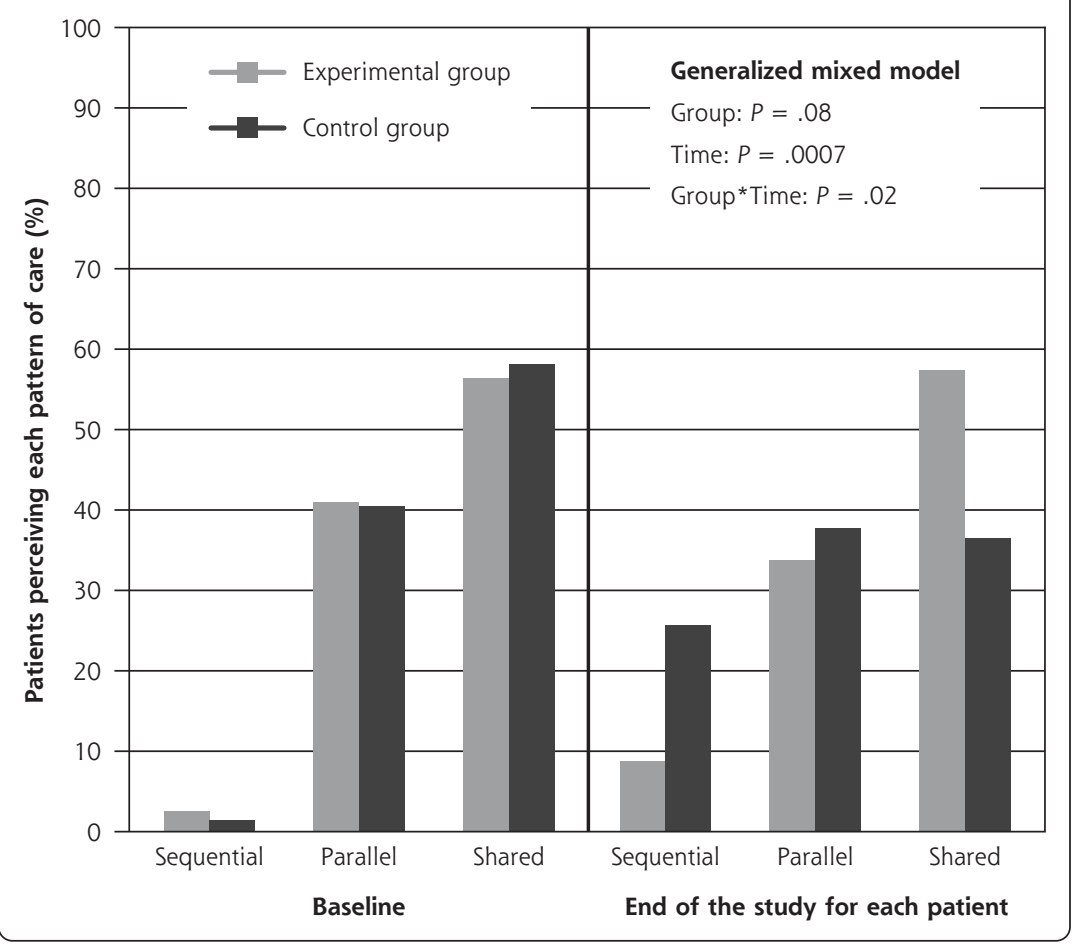




\section{Figure 4. Effect of the intervention on patient distress based on HADS.}

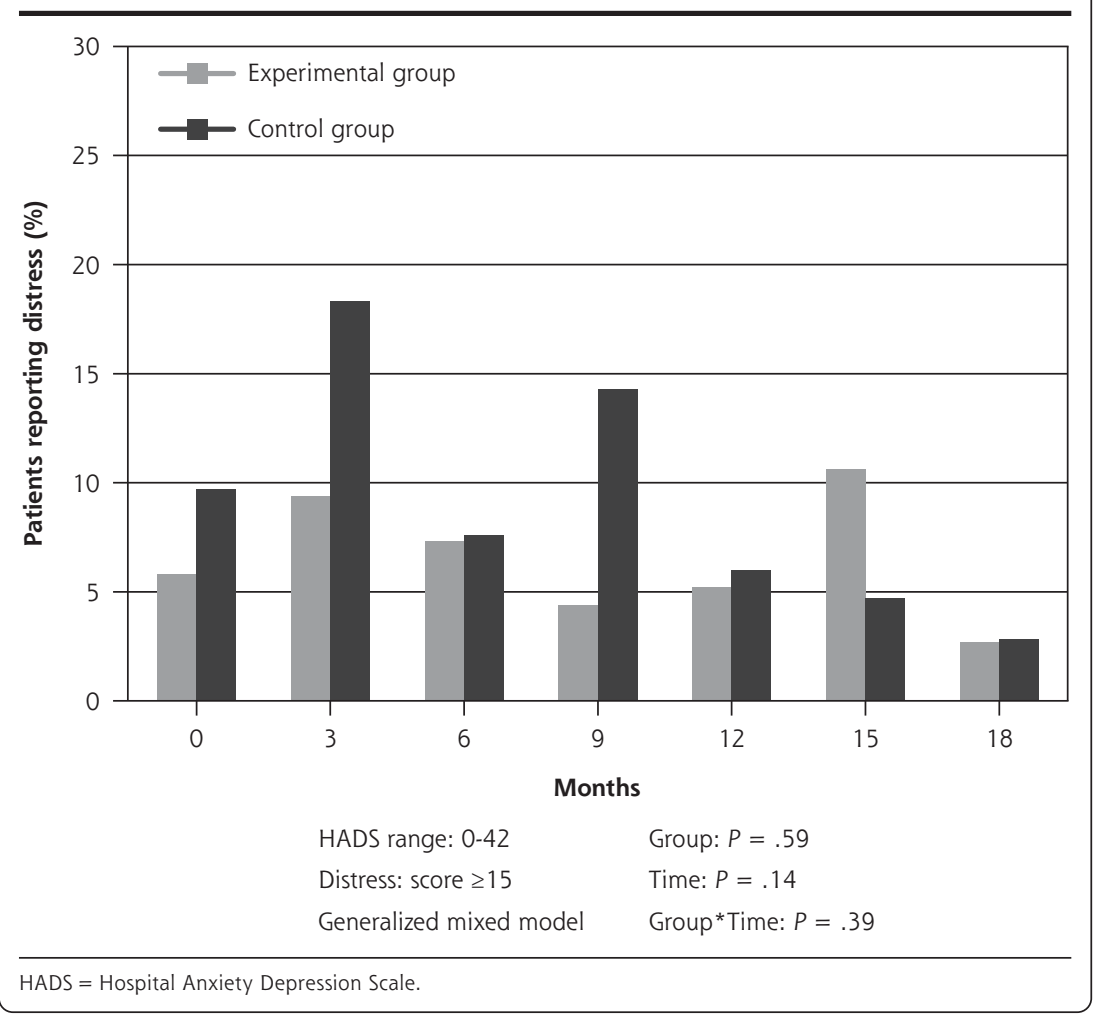

both groups continued treatment throughout the study, and they might have been overwhelmed by the number of medical visits, thus explaining the low number of FP visits. At the IUCPQ, nurse navigators usually continue to follow patients throughout their cancer journey, even after the end of treatment, thus not systematically discharging them to FPs. This might also explain the low number of FP visits.

More patients in the experimental group perceived shared care at the end of the study compared to those in the control group, and this was significantly associated with a greater number of FP visits. Given that patients perceiving shared care also reported more often good informational and management continuity of care, it might be important for the oncology team to encourage patients to continue to see their FP. Patients perceived their FP pattern of care differently than their FP, likely due to a desirability bias from FPs overestimating their shared involvement in cancer care. ${ }^{20}$

This study has some limitations. The high attrition rate, owing mainly to patient death, might have underestimated the differences between the groups. A high attrition rate is inevitable in studies with patients receiving palliative care. ${ }^{41,42}$ This study was conducted in a single center and was limited to patients with lung cancer, which might decrease its external validity. The trial took place several years ago, before the generalized integration of electronic health records and use of e-mail into practice. These more recent communication strategies, however, should facilitate the exchange of information. The results are not invalidated, they simply provide a conservative effect of the intervention, probably smaller than what would be found if the trial was replicated now. Finally, as mentioned earlier, nurse navigators on the oncology team played an important role in care coordination, which might have biased the results. However, nurse navigators met with patients in both groups, potentially introducing a nondifferential information bias, which generally decreases the ability to detect a difference between groups.

Regardless of any potential limitations, the present results provide valuable information regarding potential strategies to consider to bridge the gap between 
primary care and oncology care. Future research should refine this intervention and test it in multiple centers with different organizations of care treating patients with other types of cancer.

To read or post commentaries in response to this article, go to https://www.AnnFamMed.org/content/19/2/117/tab-e-letters.

Key words: continuity of care; interprofessional collaboration; lung cancer; oncology care; family physician; randomized clinical trial

Submitted September 16, 2019; submitted, revised, June 23, 2020; accepted June 29, 2020.

Author affiliations: Département de médecine familiale et médecine d'urgence, Université Laval, Quebec, Canada (M.A., L.V.); Centre de recherche de I'Institut universitaire de cardiologie et de pneumologie de Quebec (IUCPQ), Quebec, Canada (M.A., S.S., L.V.); VITAM - Centre de recherche en santé durable, Quebec, Canada (M.A., R.V., J.D., S. Dumont, A.T.); Département des sciences de la santé, Université du Québec à Chicoutimi, Quebec, Canada (S.S.); Département de médecine familiale et médecine d'urgence, Université de Montréal, Quebec, Canada (E.H., S. Daneault); Faculté des sciences infirmières, Université Laval, Quebec, Canada (J.D., L.F.; S.Dumont); Centre de recherche du Centre hospitalier universitaire de Québec, Québec, Canada (L.F.); Faculté des sciences sociales, Université Laval, Québec, Canada (S. Dumont); Centre d'excellence sur le vieillissement de Québec, Centre intégré universitaire de santé et de services sociaux de la CapitaleNationale, Québec, Canada (A.T., R.V.); Centre de recherche de I'institut universitaire de gériatrie de Montreal, Québec, Canada (S. Daneault).

Funding support: This study was funded by the Canadian Cancer Society-Ontario Division, Grant \#020097. A grant from the Canadian Institutes of Health Research Team for Supportive Cancer Care (Grant \#ACQ83559) supported the development of the intervention and the assessment of its acceptability before its implementation in this trial.

Previous presentations: Preliminary results of this trial were presented at the $39^{\text {th }}$ Annual Meeting of the North American Primary Care Research Group; November 14, 2011; Banff, Alberta, Canada. The abstract of this presentation has been published in the journal Family Medicine: Aubin M, Vézina L, Verreault R, et al. Experience of continuity of care in patients with lung cancer at the beginning of their treatments: preliminary results. Fam Med. 2012;44(Suppl 1):11.

ClinicalTrials.gov reference number NCT01389739

Acknowledgments: The authors thank the members of the IUCPQ ambulatory pulmonary oncology team and the patients with lung cancer who participated in this study.

Supplemental materials: Available at https://www.AnnFamMed. org/content/19/2/117/suppl/DC1/.

\section{References}

1. Taplin $\mathrm{SH}$, Rodgers $\mathrm{AB}$. Toward improving the quality of cancer care: addressing the interfaces of primary and oncology-related subspecialty care. J Natl Cancer Inst Monogr. 2010;2010(40):3-10.

2. Sussman J, Baldwin LM. The interface of primary and oncology specialty care: from diagnosis through primary treatment. J Natl Cancer Inst Monogr. 2010;2010(40):18-24.

3. Institute of Medicine and National Research Council. From Cancer Patient to Cancer Survivor: Lost in Transition. The National Academies Press; 2006. Accessed Jan 11, 2021. https://doi.org/10.17226/11468

4. The College of Family Physicians of Canada. Vision, mission, values, and goals: four principles of family medicine. Accessed Jan 11, 2021. https://www.cfpc.ca/principles/

5. Starfield B. Primary Care: Balancing Health Needs, Services, and Technology. Revised edition. Oxford University Press; 1998.
6. Rubin G, Berendsen A, Crawford SM, et al. The expanding role of primary care in cancer control. Lancet Oncol. 2015;16(12):1231-1272.

7. Aubin $M$, Vézina $L$, Verreault $R$, et al. Family physician involvement in cancer care follow-up: the experience of a cohort of patients with lung cancer. Ann Fam Med. 2010;8(6):526-532.

8. Klabunde $\mathrm{CN}$, Ambs A, Keating NL, et al. The role of primary care physicians in cancer care. J Gen Intern Med. 2009;24(9):1029-1036.

9. Lawrence RA, McLoone JK, Wakefield CE, Cohn, RJ. Primary care physicians' perspectives of their role in cancer care: a systematic review. J Gen Intern Med. 2016;31(10):1222-1236.

10. Dossett LA, Hudson JN, Morris AM, et al. The primary care provider (PCP)-cancer specialist relationship: a systematic review and mixedmethods meta-synthesis. CA Cancer J Clin. 2017;67(2):156-169.

11. Shen MJ, Binz-Scharf M, D'Agostino T, et al. A mixed-methods examination of communication between oncologists and primary care providers among primary care physicians in underserved communities. Cancer. 2015;121(6):908-915.

12. Sada YH, Street RL Jr, Singh H, Shada RE, Naik AD. Primary care and communication in shared cancer care: a qualitative study. Am J Manag Care. 2011;17(4):259-265.

13. Starfield B. William Pickles Lecture. Primary and specialty care interfaces: the imperative of disease continuity. Br J Gen Pract. 2003; 53(494):723-729.

14. Tremblay D, Latreille J, Bilodeau K, et al. Improving the transition from oncology to primary care teams: a case for shared leadership. J Oncol Pract. 2016;12(11):1012-1019.

15. Tomasone JR, Brouwers MC, Vukmirovic M, et al. Interventions to improve care coordination between primary healthcare and oncology care providers: a systematic review. ESMO Open. 2016;1(5): e000077.

16. Haggerty JL, Reid RJ, Freeman GK, Starfield BH, Adair CE, McKendry R. Continuity of care: a multidisciplinary review. BMJ. 2003; 327(7425):1219-1221.

17. Reid R, Haggerty J, McKendry R. Defusing the Confusion: Concepts and Measures of Continuity of Care. Fondation Canadienne de la Recherche sur les Services de Santé; 2002.

18. Aubin $M$, Giguère $A$, Martin $M$, et al. Interventions to improve continuity of care in the follow-up of patients with cancer. Cochrane Database Syst Rev. 2012;7:CDC007672.

19. Waibel S, Henao D, Aller MB, Vargas I, Vázquez ML. What do we know about patients' perceptions of continuity of care? A meta-synthesis of qualitative studies. Int J Qual Health Care. 2012;24(1):39-48.

20. Aubin $M$, Vézina $L$, Verreault $R$, et al. Patient, primary care physician and specialist expectations of primary care physician involvement in cancer care. J Gen Intern Med. 2012;27(1):8-15.

21. Aubin $M$, Vézina $L$, Verreault $R$, et al. Family physician involvement in cancer care and lung cancer patient emotional distress and quality of life. Support Care Cancer. 2011;19(11):1719-1727.

22. Gagliardi AR, Dobrow MJ, Wright FC. How can we improve cancer care? A review of interprofessional collaboration models and their use in clinical management. Surg Oncol. 2011;20(3):146-154.

23. Bowling A. Measuring Disease: A Review of Disease-Specific Quality of Life Measurement Scales. Open University Press; 1995.

24. Norman A, Sisler J, Hack T, Harlos M. Family physicians and cancer care. Palliative care patients' perspectives. Can Fam Physician. 2001; 47:2009-2012, 2015-2016.

25. Nielsen JD, Palshof T, Mainz J, Jensen AB, Olesen F. Randomised controlled trial of a shared care programme for newly referred cancer patients: bridging the gap between general practice and hospital. Qual Saf Health Care. 2003;12(4):263-272.

26. Haggerty JL, Pineault R, Beaulieu MD, et al. Room for improvement: patients' experiences of primary care in Quebec before major reforms. Can Fam Physician. 2007;53(6):1056-1057. 
27. Haggerty JL, Pineault R, Beaulieu MD, et al. Practice features associated with patient-reported accessibility, continuity, and coordination of primary health care. Ann Fam Med. 2008;6(2):116-123.

28. Haggerty JL, Roberge D, Freeman GK, Beaulieu C. Experienced continuity of care when patients see multiple clinicians: a qualitative metasummary. Ann Fam Med. 2013;11(3):262-271.

29. Cassady CE, Starfield B, Hurtado MP, Berk RA, Nanda JP, Friedenberg LA. Measuring consumer experiences with primary care. Pediatrics. 2000;105(4 Pt 2):998-1003.

30. Shi L, Starfield B, Xu J. Validating the adult primary care assessment tool. J Fam Pract. 2001;50(2):161.

31. Zigmond AS, Snaith RP. The hospital anxiety and depression scale. Acta Psychiatr Scand. 1983;67(6):361-370.

32. Savard J, Laberge B, Gauthier JG, Ivers H, Bergeron MG. Evaluating anxiety and depression in HIV-infected patients. J Pers Assess. 1998; 71(3):349-367.

33. Nyweide DJ, Bynum JPW. Relationship between continuity of ambulatory care and risk of emergency department episodes among older adults. Ann Emerg Med. 2017;69(4):407-415.e3.

34. Tammes P, Purdy S, Salisbury C, MacKichan F, Lasserson D, Morris RW. Continuity of primary care and emergency hospital admissions among older patients in England. Ann Fam Med. 2017;15(6):515-522.

35. Barker I, Steventon A, Deeny SR. Association between continuity of care in general practice and hospital admissions for ambulatory care sensitive conditions: cross sectional study of routinely collected, person level data. BMJ. 2017;356:j84.
36. Hudson BF, Best S, Stone P, Noble TB. Impact of informational and relational continuity for people with palliative care needs: a mixed methods rapid review. BMJ Open. 2019;9(5):e027323.

37. Easley J, Miedema B, Carroll JC, O’Brien MA, Manca DP, Grunfeld E. Patients' experiences with continuity of cancer care in Canada: results from the CanIMPACT study. Can Fam Physician. 2016;62(10): 821-827.

38. van Walraven C, Oake $N$, Jennings A, Forster AJ. The association between continuity of care and outcomes: a systematic and critical review. J Eval Clin Pract. 2010;16(5):947-956.

39. O'Toole E, Step MM, Engelhardt K, Lewis S, Rose JH. The role of primary care physicians in advanced cancer care: perspectives of older patients and their oncologists. J Am Geriatr Soc. 2009;57(Suppl 2):S265-S268.

40. Sedgwick P, Greenwood N. Understanding the Hawthorne effect. BMJ. 2015;351:h4672.

41. Higginson IJ, Evans CJ, Grande G, et al; MORECare. Evaluating complex interventions in end of life care: the MORECare statement on good practice generated by a synthesis of transparent expert consultations and systematic reviews. BMC Med. 2013;11:111.

42. Dussel V, Orellana L, Soto N, et al. Feasibility of conducting a palliative care randomized controlled trial in children with advanced cancer: assessment of the PediQuest Study. J Pain Symptom Manage. 2015;49(6):1059-1069. 